Discourse and Communication for Sustainable Education, vol. 10, no. 1, pp. 20-36, 2019

\title{
The Need for a Sustainable and Balanced Critical Approach in Book Reviews
}

\author{
Cuneyt Demir \\ University of Siirt, Siirt, Turkey
}

\begin{abstract}
Book reviews are important in offering guidance to prospective readers. What is expected from them is to be not only informative and evaluative but also unbiased and balanced. Therefore, the use of correct discourse is necessary to prevent asymmetrical domination of the reviewer, and to create a healthy setting to sustain credibility of book reviews in terms of prospective readers. In that sense, this study investigated two discourse devices, namely euphemism and dysphemism. Euphemism can be defined as polite and agreeable words or expressions that are used in place of harsh or offensive ones; however this research investigated if these expressions might lead to undue praise for a book. On the other hand dysphemism is a kind of language that uses disparaging and derogatory terms instead of complimentary or neutral ones. Reviewers may consciously or unconsciously use these linguistic devices in their critiques of books, however; the balance between them is of great importance because any unbalanced negative or positive critical act may bring about unfair judgements in would-be readers regarding the quality of the mentioned book. The present study investigated a hundred book reviews and picked up euphemistic and dysphemistic expressions. The result is of importance in helping the book reviewers to choose the true word of expression without being unnecessarily soft or offensive. Any possible biases against a book because of book reviewers' inattentive word selection may be prevented in view of the present study. Finally, this study is important for instructors of academic writing to increase their awareness for the importance of discourse devices in book reviews, which is necessary for sustainable development of education; in other words, instructors of academic writing at universities may rearrange their instruction curriculums through saving a slot for euphemism and dysphemism for prospective students.
\end{abstract}

Keywords: euphemism, dysphemism, writing, book review, criticism.

\section{Introduction}

It is almost two decades that the concept of education for sustainable development (ESD) has taken its prominent position in the curriculum with relation to all learning types ranging from environmental to economic and social issues. Although ESD is considered to be a self-learning style of an individual, it provides an education setting 
for people from all educational levels and races to realise life-long learning purpose. In a report published in 2010, Council of the European Union diversified the description of ESD and underlined that it is not confined to formal education but non-formal and informal learning. Given the widespread scope of ESD, it will not make sense not to mention the importance of it in linguistic academia. Quite a few studies in linguistics aim to create learning medium for readers to sustain their development on the discussed issues as in the present study. This study focussed on discourse that book reviewers used in their evaluation of books so that some standards could be developed in book review processes in which there are no exact rules: reviewer completely feel free to say whatever s/he wants through an infinite number of words. However, some words should be avoided not to disturb the delicate balance of objectivity of texts: euphemistic and dysphemistic words.

Euphemism helps to strike a balance between being offensive and accurate (Abrantes, 2005) while dysphemism is the deliberate or incautious use of pejorative words instead of mitigated ones. However, there may be a concealing intention embedded in them because there are times that the interaction between the speaker and the listener is not unbiased. The communication, occurring between the speaker's true intention and the listener, is to be a reciprocal co-ordination if true meaning-conveying is desired. Steering the meaning by using the advantage of the control over the communication, the speaker may severely disrupt the impartiality of the discourse, which would be completely unwanted.

From attentively prepared academic writing to arbitrary daily scripts, there are different types of writing. But no matter what it is written for, it is to be objective, particularly if it has an impact on the views of receivers like book reviews in which would-be readers will be interested in the opinion to decide whether the book is right for them. On that account, one genre in writing that has attracted international attention is the academic book review. Its principle purpose in academic journals is not only to inform the prospective readers about new books but also (Moreno \& Suarez, 2008) "to evaluate the scholarly work of a professional peer within the scholarly community" (Lindholm-Romantschuk, 1998, p. 40). The reviewer makes an argument which is almost always a commentary, not simply a summary. This critical assessment of the content bears some significant signs through clear suggestions or concealed implications for the possible audience of the reviewed book. Depending on the stance of the reviewer or on the critical evaluation, the reader will make a decision on whether the book is worth reading or not. While writing a book review, reviewers may unconsciously have negative or positive critical opinions regarding the book but they should use an attentive language in their criticism, and avoid excessive use of euphemistic or dysphemistic words because redundant use of them may undeservedly steer the readers on buying the book while the lavish use of them may discourage the possible buyers.

Euphemistic expressions (EE) is a discourse device used to express an unpleasant situation through mitigated or less harsh words while Dysphemistic expressions (DE) is the vice-versa; i.e., to express a pleasant/unpleasant situation with boosted or harsh words; however without a balanced act EE may be used to conceal something unpleasant as a face saving strategy while dysphemistic expressions (DE) may downgrade the value of a script. Now that they are linguistic devices that may exploit the books reviewed, what is the motivation for the use of these linguistic devices? A writer will use euphemism 
either consciously or unconsciously (Rawson, 1981) as it is with dysphemism, but it seems that some reviewers are not aware of the potential adverse effects of inattentive use of them. In other words, the unbalanced use of these discourse devices by the reviewers is not a conscious act but unconscious. The asymmetrical domination of these linguistic devices disrupts the discourse that should be based upon consensual agreement on meaning.

In brief, to sustain a healthy communication between interlocutors, a common code should be created between the book reviewer and the reader because the discursive collaboration may be distorted easily if the content is not conveyed through accurate way of expression (Abrantes, 2005). The selection of a word or phrase is a result of elaborative cognitive processes rather than spontaneous acts, and the true selection of a word in situations where words have ultimate power on readers as in book reviews is a must to prevent unsymmetrical domination of the reviewer on readers (Abrantes, 2005). It should be kept in mind that sustainability of education can only be developed through neutrality because a biased evaluation will not survive long. Accordingly, this study investigated a hundred book reviews and picked up euphemistic and dysphemistic words and phrases. The results are important in two-fold; to raise awareness for the book reviewers to choose the true word of expression without being unnecessarily complimentary or offensive, and to provide a fair sustainability of book reviewing processes, which is necessary to build a free setting in which readers can decide on the quality of the reviewed book. One of the pedagogical approaches in ESD is thinking creatively for future scenarios. In line with that reality, this study aims to prevent any possible biases against a book that reviewers may evoke on prospective readers of the reviewed book through unbalanced use of EE and DE, and to provide suggestions for future book reviewers in order to sustain impartiality of book evaluations.

\section{Literature Review}

Most readers have stumbled on books that are precious to them while many others have lost time and money because they bought books of no worth; however, buying a book is not a rolling the dice work but a work that needs paying attention. The question of 'How can I find the book that I need?' has necessitated the need for book reviews. Having read the review, you may decide if you would have interest for a particular book or not. This process is important for the possible readers in that book reviews are convenient to spot the best books by providing precise information about the reviewed book, which means that readers will not lose money and time thanks to the chance of discovering the book before buying it. In a similar way it is crystal clear that book reviews are important for the authors as well because if the author gets a shining review that sparkles with acclaim, the publicity together with the increasing sales will synchronously increase.

Book reviews are not mere summaries or mere praise statements (Oinas \& Leppälä, 2013) but function mostly as evaluative. Accordingly International Sociology Reviews notes that 'ISR is a vehicle for considering, examining, analysing, appraising, and evaluating books by sociologists all over the world'. While making this evaluative work, it should not be taken for granted that the discourse a reviewer would have may have a positive or negative impact on the possible readers. For example too many euphemistic words in 
expressing a weakness of a book may create an undeserved praise while dysphemistic words may have a counter-effect. Therefore, particularly these linguistic devices, namely euphemism and dysphemism, shall to be used carefully so as not to have an undesired effect on the reviewed book. According to a 2014 survey by Bright Local 84\% of readers do not trust a personal recommendation because it may be biased, which is why book reviewers are to be sensible of the discourse that they use in their reviews. A positive review to inflate the image of the book may cause a black hat (unethical) marketing, which would end up with books thrown away by desperate readers. Therefore what matters the most is not book reviews but genuine book reviews that had been prepared to show the value of the literary work but not the value of the author or the personal opinion of the reviewer. Book reviewers are not book coaches that promote or demote the literary book for marketing but are objective readers that submit the true values of the book through an honest review. They should not forget that through the snowball effect one review may beget another and the positive ranking may change all booksellers algorithm.

Another problem is the source where the review was published. Unfortunately, some editors and referees do not appear to be sensible of realising the importance of the linguistic devices that a reviewer would use. Therefore, readers are more prone to trusting book reviews published in respected sources than other sources where the editors or referees do not care about the language used in a book review. An editor or referee should be aware of the linguistic devices that the reviewer may hide to convince the possible readers or the linguistic devices that the reviewer accidentally use in steering the readers. Therefore, while assessing a book's weaknesses, the reviewer should use a balanced language free from any wrong inducement like denigrating or extoling the author, which is the duty of editors and referees to check. In brief the endorsements from a reviewer should be checked carefully by the editors and referees not to misguide possible readers.

Book reviews are poorly appreciated because they are thought as a mere marketing gimmick and they include uncritical statements of praise (Obeng-Odoom, 2014). Therefore, another role of a reviewer is to create a space for the readers to fill themselves through the language s/he uses, which is to say reviews should not include decisive words like boosters that may compel for a buy feeling or hedging words that may adversely affect the credibility of the quality of the literary work. The reader should feel independent to buy or not to buy a book because the decision is his/her own to make. Although boosters and hedges are discourse markers that may affect the genuineness of the statements, they do not distort the meaning because they are used either to create an emphatic impression on the reader or to mitigate the statements to avert possible criticism from the readers. On the other hand, euphemism and dysphemism can be deceptive by disguising something unpleasant or pleasant with carefully picked up words. More important, EE and DE can easily mislead a reader if they are not used appropriately; this is why they are two important metadiscourse devices that reviewers should be aware of.

Although thought functioning in similar ways, there should be made a clear distinction among euphemism, hedging and circumlocution. Not to be seen offensive or to avoid any criticism, the reviewers need to be careful while expressing their ideas by either using hedges or circumlocution; however, the use of hedges may prevent conveying the true intention of the writer while circumlocution, a vague language, may unwillingly 
disrupt the fluency of writing. Therefore, euphemism is of importance to get rid of the infelicities that hedges and circumlocution may bring. Similarly, conventional euphemism is used as a face-saving strategy not to be offensive. Official euphemism is used as a hedging device strategically motivated to avoid negative reference. Different designations evoke different mental pictures (harsh or soft words that are refereeing to the same things). It may be thought that euphemism veils the truth about something by distorting the meaning through $\mathrm{EE}$. This veiling is inaccurate because what is done is not to change the true intention of the author but the way of expression not to lose face or to avoid being unnecessarily offensive. In that sense, euphemism seems to be superior to other linguistic devices in creating a peaceful atmosphere while expressing your critical assessments regarding the quality of a book.

There are studies that regard euphemism as a language used to disguise taboo words in moderate words (e.g. Rabab'ah \& Al-Qarni, 2012); however, it not always an innocuous reference to a disgraceful word because when used deliberately, it may contaminate the content by camouflaging the true message that the writer intends (McGlone, Beck, \& Pfiester, 2007); It is not an innocent linguistic device that always works for the good. On the other hand, dysphemism can be used as a weapon pointed to wherever the reviewer wants as stated in Keith and Burridge's comprehensive book (1991). In sum, $\mathrm{EE}$ and $\mathrm{DE}$ are multi-dimensional linguistic devices that should not be confined into a single concept. This study was conducted to investigate how the overused of them by book reviewers may disrupt the meaning.

\section{Methodology}

\section{The Corpus}

This study was not conducted on the basis of gender and nationality of the reviewers, yet for constructing a reliable corpus, factors like gender and nationality of the reviewers were taken into consideration since gender may have an impact on discourse (Coates, 2015) as may the nationality of the writer (Saraceni, 2015). Therefore, the corpus was compiled in a way that strikes a gender balance. It is a well-established phenomenon that cultural background and thoughts may have an effect on the spoken language (c.f. Sapir-Whorf hypothesis), and similarly in his book of Cultural studies and discourse analysis Barker (2001) stated that "it is a core case of cultural studies that language does no mirror an independent object world but constructs and constitutes it (p.1)". Therefore, the present study considers that discourse devices like EE and DE may show differences depending on the nationality of a reviewer, and a corpus collected from reviewers from different cultural background might disturb the reliability of the data. Because homogeneity is crucial to sustain data reliability, only reviews of Anglophonic writers were collected. The origin of names and affiliation knowledge determined whether the writers were Anglophonic or not. A mishap like a non-Anglophonic writer with an English origin name and a workplace in an English-speaking country was overlooked because of difficulty in determining such an infelicity. The corpus was seeded from journals indexed in SSCI since not all journals have same quality that pay attention to the language used in the review (Table 1). 
Table 1

Journal and Gender Distribution Across the Corpus

\begin{tabular}{lccc}
\hline \multirow{2}{*}{ Journal } & \multicolumn{2}{c}{ Gender } & \multirow{2}{*}{ Total } \\
\cline { 2 - 3 } & Male & Female & \\
\hline English for Academic Purposes & 11 & 10 & 21 \\
\hline English Language \& Linguistics & 10 & 10 & 20 \\
\hline Journal of English Linguistics & 9 & 11 & 20 \\
\hline English for Specific Purposes & 9 & 7 & 16 \\
\hline Assessing Writing & 8 & 5 & 13 \\
\hline Applied Linguistics & 6 & 4 & 10 \\
\hline Total & 53 & 47 & 100 \\
\hline
\end{tabular}

The corpus was all to be gathered from the same area of study (Language and Linguistics) because discourse devices may show differences across disciplines (Hyland, 2005). Not to cause any reliability concern, a collection of one hundred reviews were compiled from equi-length reviews. Another requirement considered to be essential to construct a corpus for critical acts analyses is the publication time of the texts that build the corpus because type of critical acts and frequency can be affected by the historical time in which the texts had been published (Salager-Meyer, 2006). On this account reviews published only in the last few years (2014-18) were collected. Since the length of the individual review is a potential confounding factor, exceptionally short or long reviews were excluded from the sample. Table 2 shows average number of words per review and total number of words per journal.

Table 2

Average and Total Number of Words per Journal

\begin{tabular}{lcc}
\hline \multicolumn{1}{c}{ Journal } & Average number of words & Total \\
\hline English for Academic Purposes & 1828 & 38385 \\
\hline English Language \& Linguistics & 1883 & 37669 \\
\hline Journal of English Linguistics & 1939 & 38785 \\
\hline English for Specific Purposes & 1566 & 25058 \\
\hline Assessing Writing & 1735 & 22566 \\
\hline Applied Linguistics & 1700 & 17000 \\
\hline Total & 1775 & 179463 \\
\hline
\end{tabular}

\section{Method for Identifying, Interpreting and Quantifying Critical Acts}

Identifying critical acts, namely EE and DE in this study, can be carried out through three basic evaluation frameworks, which are establishing an interpersonal relationship with the readers or hearer, expressing the speaker's / writer's opinion, and organising the discourse (Thompson \& Hunston, 2000). This paper evaluated the data by focussing on the second one, i.e., expressing the speaker's / writer's opinions, feelings, stance, or viewpoint on the entities that $\mathrm{s} / \mathrm{he}$ is talking about. Because a PC based word processing or concordance program would not provide with the true meaning of a word, i.e., what really a reviewer wants to convey to the readers, the corpus was analysed manually. For evaluating the corpus on a safer ground, the critical acts were not categorized by a single concordance line but by observing comprehensively the whole sentence or the paragraph 
because a successful interpretation phenomenon needs seeing the big picture rather than the fragments. For this reason, each review was wholly scanned to reveal whether the reviewer has unfairly used these linguistic devices against or in favour of the book.

Given the opaque and oblique nature of evaluation procedures, and that the evaluation of critical acts requires a lot of attention, a second evaluator should undergo to be able to establish a compendium of evaluated book reviews. For this reason, in addition to the researcher, a second rater who is specialist on the field of discourse categorized the $\mathrm{EE}$ and $\mathrm{DE}$ according to the taxonomy created for the present paper. To maintain consistency in scoring and to minimize any bias that a rater could develop, each rater independently categorized ten percent of the corpus adhered to a certain evaluation criteria. The results provided an inter-rater reliability score of .85 , which refers to a consensus or homogeneity between raters in terms of categorizing the critical acts.

The taxonomy according to which the corpus were analysed is composed of three categories for both expression types; word-based change, remodelling the phrase/sentence, and figurative expressions. Each example of EE and DE was written down into the appropriate category, and then was analysed in a way to decide whether they might unfairly affect readers' feeling towards the reviewed book. To speak more specifically about the taxonomy:

1) Word-based change is to include synonyms, antonyms, or quantifiers that change the degree of the words. If we take housekeeper and disabled words, euphemistic equivalents of them will be domestic engineer instead of housekeeper, and differently-abled instead of disabled. Similarly from a dysphemistic view, word-based change will be maid for the word housekeeper and mentally/ physically-impaired for the word disabled. Regarding quantifiers, some words may create a feeling of negative depending on the place they are used. For example while the word short is thought to be acceptable in a review, it may turn to a dysphemistic word together with too much as in the sentences 'the book is a bit short' and 'the book is too much short'. The second sentence creates a negative feeling towards the reviewed book while the first sentence does not make you feel that sense.

2) As understood from the name, remodelling phrase is an endeavour to rewrite the sentence with acceptable words, sometimes through circumlocution. For example, a book needs editing but instead of saying it abruptly one may prefer to say 'it would be much better if the book was controlled before publishing', which would be a euphemistic way of the expression. The vice-versa, which is to say the sentence abruptly instead of circumlocuting it, would be a dysphemistic way of the expression.

3) Although review writing is thought to be a formal way of writing, reviewers prefer to use a flexible language to have a wider expression of freedom. Therefore, they may include figurative speeches like idioms and proverbs in their reviews. It is possible to oversimplify or complicate a weakness of the reviewed book through euphemistic or dysphemistic figurative expressions. For instance, that a reviewer uses 'be dead in the water' instead of 'unsuccessful' may create an undue influence over would-be readers towards the book. Imagine the vice versa situation in which having received quite much criticism from the reviewer, the book would be mentioned as that has only a few minor weaknesses, which is a euphemistic phrase that gains undue respect for the book. 


\section{Results and Discussion}

Analysis results proved that book reviewers largely used EE; however, the matter, as the present study investigated, is that some euphemistic expressions are unfairly used in a way that ignoring or downplaying the seriousness of the weaknesses existed in the reviewed books. In other words, not all EE are a matter for the present study. Similarly, some DE that may create a sense of disappointment on the reader towards the reviewed book were detected in the data. The results were provided in sum in the Figure 1.

Critical Acts

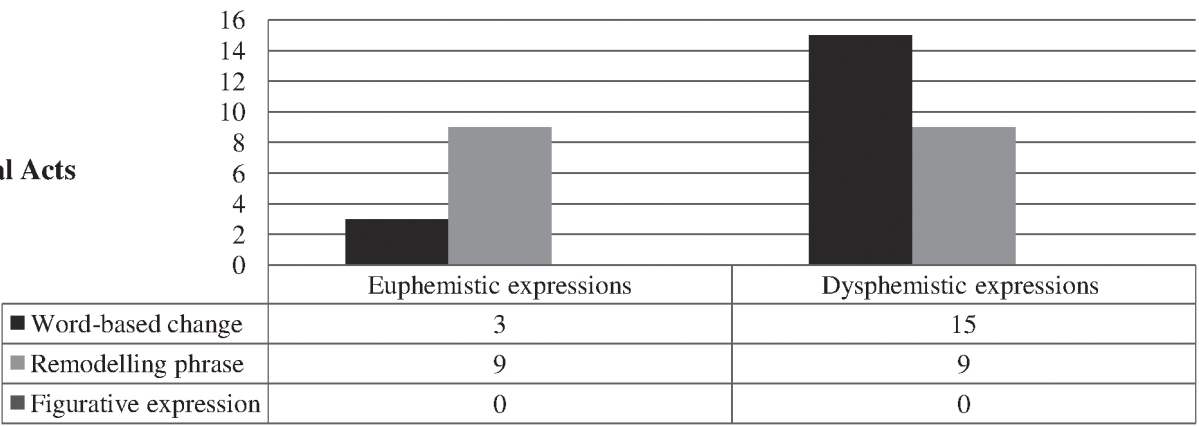

Figure 1. Total euphemistic and dysphemistic expressions in the corpus

An adding note regarding analysis results is that although EE outnumbered DE, the figure shows the vice versa, which is because not all EE were counted but only those that were unfairly used by the book reviewer. Another noteworthy finding is that no figurative expressions were found in the data, which proves that book reviewers do not include figurative expressions in a way to euphemize or dysphemize their statements. Concerning each category, only three samples were provided with an explanation due to space unavailability on this paper; the rest of the samples were given in the tables following the sub-heading.

\section{Analysis Results of Euphemistic Expressions}

I found twelve euphemistic acts; three of which are in word-based change category while nine of which are in remodelling phrase category.

\section{Word-Based Change}

All three samples that were collected from the corpus were provided under this sub-heading. The first sample is as follows:

(1a) I found the section on tasks a bit disappointing...

The word a bit seems to be used unfairly because it is a word mitigating the power of a word on the reader. Regarding the disappointing points that the reviewer mentioned in the review, I noticed that the word is just too weak because she criticized the tasks mentioned in the sentence so severely. Having criticized the tasks so rigorously in the reviewed book, she could have used a word that suits to the weakness of the book. As indicated earlier, the book should have what it should have and the word a bit mitigated 
the power of the word disappointing. In short, the author mitigated his/her statement than enough, which may have the book gained an undue respect; therefore, a word change may correct the situation as follows:

(1b) I found the section on tasks disappointing. (by leaving out the word a bit)

While the example 1a can be corrected by leaving out the quantifier a bit, the second example needs a change of verb as the reviewer prefers to use a negative sentence with a verb of pay attention as following:

(2a) More seriously, he does not pay attention to the most important aspects of...

When the review taken together, the word pay attention is too much positive for such a comment because as seen in the example the most important aspects had been overlooked by writer of the book, which is a frustrating situation. Furthermore, the reviewer starts with an introductory phrase of more seriously which signals the importance of the criticism. Therefore, the review sentence may be turned into affirmative sentence with more assertive verb that will emphasize the importance of such a weakness of the book as in:

(2b) More seriously, he ignores the most important aspects of...

The verb ignore seems to be better to underline the criticism against the book. Unnecessarily hedged sentences may not be seen as a limitation of the reviewed book by the readers. Such a situation may lead to even a praise while the real intend of the book reviewer was to criticize.

Similarly, in the last example the reviewer decreased his/her tone more than required through a linking verb of seem:

(3a) Unfortunately, she seems to miss the core structures that build...

When the sentence was taken overhaul, it is easy to feel the frustration of the reviewer even at the outset of the sentence. The word unfortunately signals unsatisfying situation while the word core signals the importance of something. In brief, although the reviewer downgrades his tone, de facto s/he touches down a very important point which is the writer of the book did not mention the very main point of something. Therefore the verb seems is too much euphemistic in this sentence and is better if taken out as follows:

(3b) Unfortunately, she misses the core structures that build...

The sentence $3 \mathrm{~b}$ informs the readers more assertively than the sentence $3 \mathrm{a}$ because the linking verb seems in $3 \mathrm{a}$ adds a sense of uncertainty to the sentence. The question of whether the writer missed or did not miss can be answered precisely with the sentence $3 \mathrm{~b}$.

\section{Remodelling Phrase}

Remodelling is the second category through which it is aimed to save sentences from unnecessary EE. Nine such samples in total were picked up in the corpus.

(1a) It would perhaps be possible to fault the book for failing to provide a more comprehensive coverage of the research literature on the areas it treats... 
A literature research is one of the most important chapters of a book. It is understood from the review sentence that the book does not have enough of it. This is a crucial addition for a book and it would be better if the reviewer had highlighted that through a sentence with boosters rather than a hedging phrase as in the original sentence. If the sentence remodelled in the light of advice, it might be more directly informative for the readers. For example:

(1b) The book lacks a more comprehensive coverage of the research literature on the areas it treats...

The phrase in the original sentence It would perhaps be possible to fault the book for failing to provide can be covered with the phrase of the book lacks. The second phrase readily takes attention on the issue mattering to the possible readers of the reviewed book while the first phrase appears to have undermined the issue of the weakness in the research literature.

(2a) It must be said that the book shows signs of having been produced in haste... (continuing... Proof-reading and other editorial slip-ups are too frequent and Pearson Education's reputation is not well served by such carelessness. There does not want to have to deal with in correct word choice and repetition of content, let alone editorial instructions that have mistakenly been left in.)

The reviewer prefers to introduce the weakness of the book through a euphemistic introductory phrase, having said that, the continuing phrases criticize the weakness of the book fiercely. Therefore, if the aim is to make fair directive comments for the possible readers, the introductory phrase is better if not presented in such because it may cause misleading. That a book published by Pearson has such errors is not a minor failing that can be dodged easily; therefore, it will be fairer to have a remodelled phrase that takes the reader's attention on the issue as in:

(2b) Unfortunately, the book contains mechanical and lingual errors.

Writing a dissertation is an arduous work for many, and factors like time and motivation are of great importance. However, because of the overdosed euphemistic phrase the expression that the reviewer used about the failing of the book on time management and motivation sounds as though the failing should not be faulted (6a).

(3a) It would have been made more comprehensive by including additional aspects such as time management, maintaining motivation, and dealing with writer's block.

A remodelled sentence would emphasize the parsimonious account of the book on time management and motivation as in $6 \mathrm{~b}$ so that the possible readers would be aware of the lacuna on these issues:

(3b) The book fails to provide sufficient information on time management and motivation.

As stated earlier, due to unavailability of space, the rest of the samples will be provided in the tables without explanation. Accordingly, the Table 3 provides other examples of remodel phrase category. 
Table 3

Other Remodelled Samples of Euphemistic Expressions from the Corpus

\begin{tabular}{|c|c|}
\hline Original Text & Remodelled Text \\
\hline $\begin{array}{l}\text { 4a Nevertheless, I look forward to a new } \\
\text { generation of EAP texts which pays due } \\
\text { regard to underlying theory and systemati- } \\
\text { cally incorporates the latest research } \\
\text { findings for study and analysis. }\end{array}$ & $\begin{array}{l}\text { 4b This EAP book does not provide new } \\
\text { generation text and also it does not pay } \\
\text { due regard to underlying theory and } \\
\text { systematically incorporates the latest } \\
\text { research findings for study and analysis. }\end{array}$ \\
\hline $\begin{array}{l}\text { a a } \begin{array}{l}\text { However, it leaves the readers demanding } \\
\text { more... }\end{array} \\
\end{array}$ & $\begin{array}{l}\text { 5b The book needs to be added with } \\
\text { further information on... }\end{array}$ \\
\hline $\begin{array}{l}\text { 6a Readers also would have benefited from } \\
\text { inclusion of an index }\end{array}$ & 6b The book do \\
\hline $\begin{array}{l}\text { 7a He also neglects mentioning any other } \\
\text { assessment contexts, such as ... }\end{array}$ & $\begin{array}{l}7 \mathrm{~b} \text { He does not } \\
\text { contexts, suc }\end{array}$ \\
\hline $\begin{array}{l}8 \mathrm{a} \text { The second area where I had hoped for } \\
\text { a more elaborated discussion was... }\end{array}$ & $\begin{array}{l}\text { 8b The chapter fails to provide an elabo- } \\
\text { rated discussion of... }\end{array}$ \\
\hline $\begin{array}{l}\text { 9a I am not always totally convinced by } \\
\text { Pearlman's arguments. }\end{array}$ & $\begin{array}{l}\text { 9b Pearlman cannot achieve to convince } \\
\text { the reader on some of his arguments. }\end{array}$ \\
\hline
\end{tabular}

\section{Analysis Results of Dysphemistic Expressions}

Compared to the euphemistic acts, it was found that dysphemistic expressions are more common across the corpus. Fifteen samples were collected in the category of word-based change while nine for remodelling category.

\section{Word-Based Change}

All books may have their weaknesses as well as strong points, but a reviewer should be careful when to talk about imperfection of a book. Too exaggerated language, as stated before, may lead to a counter-react feeling by the possible readers or the book. Therefore, to have a true balance in criticism, the reviewer should pick his/her words carefully. The first example needing a word-based change is that:

(1a) The most serious confusion of the book is on concepts of validity, due largely to Neal's reliance on single...

The words the most serious hold a very critical attitude against the book, and make the sentence rather pessimistic from the aspect of possible readers. The sentence provokes you to think of that as if 'the writer had a lot of confusion and that was the most serious one; however, the tone could be lowered without any semantic shift:

(1b) Another, maybe the most important, confusion of the book is on concepts of validity, due largely to Neal's reliance on single...

That a book misses required information for its own theme may be common because the scope of knowledge is infinite. The reviewer can find such an absence in the book, and may like to indicate that. However, when the appropriate word is not used, feeling of insufficiency may be evoked on the readers, which is an unwelcome situation. Look at the adjective of conspicuous in the example $2 \mathrm{a}$ : 
(2a) There is a conspicuous absence of works...

Instead of 'conspicuous', the meaning of which is 'very noticeable or attracting attention, often in a way that is not wanted', the reviewer could use 'obvious' which is an adjective that does not give sense of negativity because it is much more common.

(2b) There is an obvious absence of works...

Books may have imperfections that are mentioned by reviewers to inform the readers. One example is:

(3a) A noteworthy limitation is the lack of measures for assessing grammatical complexity.

A limitation is a limitation and it does not need to be highlighted with a strong adjective. The word noteworthy gives a feeling of as though the book had many limitations and the noteworthy one was that although when the whole review was read it would be seen that there were not any other limitations. Then, why to use it? Therefore, the word can be excluded or a more mitigated adjective can be used:

(3b) A (meaningful) limitation is the lack of measures for assessing grammatical complexity.

Table 4 provides other similar samples from the corpus.

Table 4

Other Word-Based Change Samples of Dysphemistic Expressions from the Corpus Original Text Word-based Change Text

$4 \mathrm{a}$ The major demerit of this part of the book, $4 \mathrm{~b}$ The major demerit of this part of the however, is its sheer long-windedness. book, however, is its $\varnothing$ long-windedness.

$5 \mathrm{a}$ It seems, however, that too much emphasis $5 \mathrm{~b}$ It seems, however, that redundant has been placed on oral presentations, compared to seminars and discussions. emphasis has been placed on oral presentations, compared to seminars and discussions.

6a This book narrows down its scope to course development in ESP, providing only a very general view on other related issues.

6b This book narrows down its scope to course development in ESP, providing exclusively a general view on other related issues.

$7 \mathrm{a} \quad$ An admitted limitation of this work is its $7 \mathrm{~b} \quad \mathrm{~A} \varnothing$ limitation of this work is its focus focus on ... on...

8a Hadley is at pains to point out throughout $8 \mathrm{~b}$ Hadley has difficulty in pointing out the book that... throughout the book that...

9a A sorry conclusion to be drawn from this 9b An average conclusion to be drawn chapter is that... from this chapter is that...

10a The important impacts of the new media 10b The important impacts of the new upon different business genres are left unexplored. media upon different business genres need to be explored.

11a It is also unclear why the discussion of teaching critical thinking is

$11 \mathrm{~b}$ Also, it is not clear why the discussion of teaching critical thinking is 
Sequel to Table 4.

12 a ...it is caused by an excessive number of cross-references to other structural parts of the book which...

13a the work refers only marginally to the expanding literature in the area of...

$14 \mathrm{a}$...these proposed principles might be too abstract to prove...

15 a ...the focus that drifts in Chapter 5 is very much lost in Chapter $6 \ldots$
$12 \mathrm{~b}$....it is caused by an inordinate number of cross-references to other structural parts of the book which...

$13 \mathrm{~b}$ the work refers slightly to the expanding literature in the area of...

$14 \mathrm{~b}$...these proposed principles might not be concrete enough to prove...

$15 \mathrm{~b}$...the focus that drifts in Chapter 5 is broadly lost in Chapter $6 \ldots$

\section{Remodelling Phrase}

Although speaking directly makes communication easier, it may cause misconception depending on the situation as in the sentence below:

(1a) ...nowhere do the authors attempt to make the book interactive or more direct.

This sample of direct speech, particularly with the word nowhere, abruptly crates a feeling of negativity; however, the sentence can get rid of from dysphemistic appearance by remodelling sentence with minor changes and addition:

(1b) Authors could make the book interactive or more direct.

In the second example (2a), we understand that the reviewer criticizes authors' failing in sticking to a single pedagogical method, but the expression seems to be tough particularly together with the words rigidly and any. A balanced remodelling of this sentence needs removing these words as in $2 \mathrm{~b}$.

(2a) The authors do not stick rigidly to any single pedagogical method.

(2b) ...that authors do not follow single pedagogical method is a limitation of them.

In the example $3 a$ the reviewer intends to make a valuable addition to the book with relation to an outdated reference; however, the addition mostly sounds like a criticism instead of a kind addition. Remodelled text of it saves the expression from being dysphemistic through a change of syntax (3b).

(3a) His only reference to psychometric principles is to the outdated 1985 edition of Standards of educational and psychological testing rather than the later 1992 or 1999 editions.

(3b) A reference to 1992 or 1999 editions of Standards of educational and psychological testing would be more up-to date rather than the earlier edition of 1985. 
Table 5

Other Remodelled Samples of Dysphemistic Expressions From the Corpus

\begin{tabular}{|c|c|}
\hline Original Text & Remodelled Text \\
\hline $\begin{array}{l}4 \mathrm{a} \text { I was unable to find anything much on } \\
\text { seminar discussion skill. }\end{array}$ & $\begin{array}{l}\text { much I found on se } \\
\text { cills. }\end{array}$ \\
\hline $\begin{array}{l}\text { 5a There is inevitably some overlap in the } \\
\text { case studies. }\end{array}$ & $\begin{array}{l}\text { 5b There exists some overlap in the case } \\
\text { studies. }\end{array}$ \\
\hline $\begin{array}{l}\text { 6a ...I wonder why she has not addressed the } \\
\text { status and the key role of web } 2.0 \text { techno- } \\
\text { logies in scholarly publication in this book. }\end{array}$ & $\begin{array}{l}\mathrm{d} \text { be better if the book included } \\
\text { nformation on the key role of } \\
0 \text { technologies. }\end{array}$ \\
\hline ay be too little, rather & need to be improved. \\
\hline $\begin{array}{l}8 \mathrm{a} \text { the AWC described in this book lacks a } \\
\text { holistic score. }\end{array}$ & $\begin{array}{rr}8 \mathrm{~b} & \mathrm{~A} \mathrm{~h} \\
& \text { des }\end{array}$ \\
\hline $\begin{array}{l}\text { 9a Neal also fails to mention or discuss the } \\
\text { Godshalk, Swineford, and Coffman... }\end{array}$ & $\begin{array}{c}\text { 9b Not to fall short, Neal could discuss } \\
\text { Godshalk, Swineford, and Coffman... }\end{array}$ \\
\hline
\end{tabular}

In sum, the results found twelve EE and twenty-four DE that were used in a way that might negatively affect the readers. DE outnumbered EE, which shows that reviewers consciously or unconsciously tend to use a derogatory language instead of neutral or pleasant one in their criticisms. Similarly, although marginally, it was found that reviewers may become too mild or indirect in their criticism against a book by using excessive euphemism. The use of both expressions disproportionately is to be considered inappropriate in terms of evaluation credibility because of the possible unfair impact on the reader.

Euphemism is almost always regarded as an innocent device that is used to be polite or indirect as a face-saving effort; however, the reality shown in the present study concludes that it is not blameless. Deliberately using an oblique language or immoderate face-saving acts through euphemism in book reviews may impede the revelation of true value of a book by masking the reality. Accordingly, unbalanced use of these discourse devices may assuage or aggravate the readers' feelings towards the book, hence, may steer readers to the wrong ports of destination, which is a damaging situation for the credibility and sustainability of future book reviews.

\section{Conclusion}

Reviews have two basic purposes: to inform the possible readers about the content of the book and to provide an evaluation regarding the strong and weak points of the book. While achieving these aims, the reviewer should strike a good balance so as not to create an advantageous or disadvantageous atmosphere for the book, which may lead to biased evaluation. To able to sustain a fair balance, the underlying power of critical acts must be kept in mind. Of many discourse devices two of them, particularly those thought to be important, were investigated in this study: euphemistic and dysphemistic expressions; they are multi-dimensional linguistic devices that should not be confined to a single innocent concept because any asymmetrical domination of these linguistic devices may disrupt the discourse that should be based upon consensual agreement on meaning and the ramification of such a situation would be undue praise 
or criticism of a book. On that account, this study was conducted to investigate how failed euphemistic and dysphemistic expressions of book reviewers may disrupt the meaning, hence, the image of the reviewed book for the possible readers. It was also aimed to conceptualize why to avoid inattentive word selection of these expressions to prevent any possible biases against a book. In spite of the magnitude of the corpus, this study did not revealed an immoderate number of these critical acts, yet the results are of importance in building awareness amongst reviewers in terms of negativity that could occur due to careless word use. Undoubtedly, the reviewer is expected to obviously express his/her reservations or praises towards the book because "no book review should be just praise" (Tracy, 1997, p. 117) or just criticism. The suggestion is that an evaluation in a book review should be saved from side effects of exaggerated use of euphemism and dysphemism not to cause an unfair setting for the reviewed book.

In a globalising world, inter-dependency between individuals and societies are gradually becoming more apparent, even obligatory. You are never free from a wrongdoing performed on the other side of the world because of innovative initiatives and technology. Each individual should take action responsibly to leave a sustainable life for the future generations and education is certainly not an exception. To sustain overarching importance of education for the better, we need to upgrade our education system in a way that impartiality would have the due respect. Despite still developing, academic writing education is gradually gaining weight in education system especially in the tertiary circle. Students are taught that a sentence is not only a cluster of words but more than that with its underlying and intended messages. Students are forced to consider about ramifications of inattentive word selection in any piece of academic writing, in which the importance of discursive devices comes out because they may readily steer a reader if not used objectively. This study suggests attentive use of euphemistic and dysphemistic expressions in book reviews, and highly advices academics who give lectures on academic writing not to take the importance of the findings of the present study for granted. A book review writing is not an arbitrary phenomenon; therefore, academic should mention why an objective language is important in a review writing because what we do have implications on the lives of people and the planet in the future (UNESCO, Education for Sustainable Development, 2018). In concise, the present study aimed to investigate how a careless language in book reviews could negatively affect the book as well as readers' decision on buying the book. Last, by building awareness regarding the importance of a balanced language in book review, this study aimed to mark the necessity of sustainable education, which is an issue that has been rigorously researched by academics from a wide range of fields (Salite, 2008; Pipere, 2016; Franzenburg, 2017; Hiller \& Reichhart, 2017). The importance of objective language in book reviews is recommented to be added into contents of any courses on academic writing because it should not be forgotten that "Working towards sustainable education will demand whole system reform (Branden, 2012, p. 299)"

This study did not draw any distinction based on gender differences, and investigated reviews only on ELT not to expand the scope of the aim to be able to better focus on it. Although there are a few studies that were investigated gender based euphemism (e.g. Fernandes, 2008; Fern Andex, 2015; Li \& Xie, 2017), the research scopes of them are different from the one suggested here; therefore, further research can shed light on these issues. 


\section{References}

Abrantes, A. (2005). Euphemism and co-operation in discourse. In E. Grillo, Power without dominations: Dialogism and the empowering property of communication (pp. 85-103). Amsterdam: John Benjamins.

Barker, C. (2001). Cultural studies and discourse analysis: A dialogue on language and identity. Sage.

Branden, K. (2012). Sustainable education: basic principles and strategic recommendations. School Effectiveness and School Improvement, 23(3), 285-304. doi: 10.1080/09243453.2012.678865

Burridge, K., \& Keith, A. (1991). Euphemism and dysphemism: Language used as shield and weapon. New York: Oxford University Press.

Coates, J. (2015). Women, men and language: A sociolinguistic account of gender differences in language. Routledge.

Fern Andex, E. (2015). Sex in language: Euphemistic and dysphemistic Metaphors in internet forums. London: Bloomsbury Publishing.

Fernandes, E. (2008). Sex-related euphemism and dysphemism: An analysis in terms of conceptual metaphor. Atlantis, 30(2), 95-110.

Franzenburg, G. (2017). Learning from the past for the future: How to make adult education sustainable. Discourse and Communication for Sustainable Education, 8(2), 57-65. doi: https://doi.org/10.1515/dcse-2017-0015

Hiller, K., \& Reichhart, B. (2017). Motivation of civic education teachers-in-training in the field of education for sustainable development. Discourse and Communication for Sustainable Education, 8(1), 81-89. doi: https://doi.org/10.1515/dcse-20170006

Hyland, K. (2005). Stance and engagement: a model of interaction in academic discourse. Discourse Studies, 7(2), 173-192.

Li, B., \& Xie, C. (2017). Sex in language: Euphemistic and dysphemistic Metaphors in internet forums. Australian Journal of Linguistics. doi: https://doi.org/10.1080/ 07268602.2017 .1291262

Lindholm-Romantschuk, Y. (1998). Scholarly book reviewing in the social sciences and humanities: The flow of ideas within and amongst disciplines. Westport: CT: Green Press.

McGlone, M., Beck, G., \& Pfiester, A. (2007). Contamination and camouflage in euphemisms. Communication Monographs, 73(3), 261-282.

Moreno, A. I., \& Suarez, L. (2008). A study of critical attitude across English and Spanish academic book reviews. Journal of English for Academic Purposes, 7, 15-26.

Moreno, A., \& Suarez, L. (2008). A study of critical attitude across English and Spanish academic book reviews. Journal of English for Academic Purposes, 7, 15-26.

Obeng-Odoom, F. (2014). Why write book reviews? Australian Universities' Review, $56(1), 78$.

Oinas, P., \& Leppälä, S. (2013). Views on book reviews. Regional Studies, 47(10), 1785-1789.

Pipere, A. (2016). Envisioning complexity: Towards a new conceptualization of educational research for sustainability. Discourse and Communication for Sustainable Education, 7(2), 68-91. doi: https://doi.org/10.1515/dcse-2016-0017

Rabab'ah, G., \& Al-Qarni, A. (2012). Euphemism in Saudi Arabic and British English. Journal of Pragmatics, 44, 730-743. 
Rawson, H. (1981). A dictionary of euphemism and other doubletalk. New York: Crown Publishers.

Salager-Meyer, F. (2006). From "Mr. Guthrie is profoundly mistaken.” to "Our data do not seem to confirm the results of a previous study on.": a diachronic study of polemicity in academic writing (1810-1995). Iberica, 1, 5-28.

Salite, I. (2008). Educational action research for sustainability: Constructing a vision for the future in teacher education. Journal of Teacher Education for Sustainability, $10,5-16$.

Saraceni, M. (2015). World Englishes: A critical analysis. Bloomsbury Publishing.

Thompson, G., \& Hunston, S. (2000). Evaluation in text. Authorial stance and the construction of discourse. In \&. G. S. Hunston, Evaluation: an introduction (pp. 127). Oxford: Oxford University Press.

Tracy, K. (1997). Constructing an academic book review. Human Studies, 20, 117123.

UNESCO. (2018). Education for Sustainable Development. Retrieved 11, 4, 2018 from UNESCO: https://en.unesco.org/themes/education-sustainable-development-esd

Correspondence concerning this paper should be addressed to Cuneyt Demir, PhD, at the unit of Interpreting and Translation, University of Siirt, Kezer Kampusü, Yabancı Diller Yüksekokulu, Siirt/Turkey. Email: ardgelen@hotmail.com 